\title{
Mechanical properties and cytotoxicity of experimental soft lining materials based on urethane acrylate oligomers
}

\author{
Takahito KANIE¹, Koichi TOMITA², Masayuki TOKUDA², Hiroyuki ARIKAWA¹, Koichi FUJII' and Seiji BAN \\ ${ }^{1}$ Department of Biomaterials Science, Graduate School of Medical and Dental Sciences, Kagoshima University, 8-35-1 Sakuragaoka, Kagoshima \\ 890-8544, Japan \\ ${ }^{2}$ Restorative Dentistry and Endodontology, Dentistry, Kagoshima University Hospital, 8-35-1 Sakuragaoka, Kagoshima 890-8544, Japan \\ Corresponding author, Takahito KANIE; E-mail: einak@ms.kagoshima-u.ac.jp
}

\begin{abstract}
The purpose of this investigation was to determine whether experimental light-curing soft lining materials (ESLMs) based on commercially available urethane acrylate oligomers (UA-160TM, UV-3200B, UV-3500BA, and UV-3700B) are suitable for clinical use by measuring their viscosity, compressive modulus, Shore A hardness, tensile strength, adhesive strength, and cytotoxicity. The viscosities of the four ESLMs at $25^{\circ} \mathrm{C}$ were $10.5 \mathrm{~Pa} \cdot \mathrm{s}$, UV-3500BA; $144.0 \mathrm{~Pa} \cdot \mathrm{s}, \mathrm{UA}-160 \mathrm{TM} ; 328.8 \mathrm{~Pa} \cdot \mathrm{s}, \mathrm{UV}-3700 \mathrm{~B}$; and $1079.7 \mathrm{~Pa} \cdot \mathrm{s}$, UV-3200B. Polymerized UV-3700B was very soft, whereas the softness of the other ESLMs was similar to that of conventional soft lining materials. No significant difference in adhesive strength was observed between UV-3500BA and UV-3700B at 1 day and those at 12 months. Cytotoxicity was measured by a MTT-based assay using HeLa S3 and Ca9-22 cells. UV-3200B and UV-3700B oligomers and all four polymerized ESLMs showed cell viability over 95.2\% $(p<0.05)$.
\end{abstract}

Keywords: Soft lining material, Mechanical property, Cytotoxicity

Received Jan 27, 2009: Accepted Mar 18, 2009

\section{INTRODUCTION}

As the number of patients with dentures has increased, requests for improvements to certain features, such as surface hardness, have also grown. Some patients with complete dentures are satisfied with the masticatory ability provided by the soft lining materials, while others use adhesives or home reliners between the dentures and oral soft tissues ${ }^{1-3)}$ to increase the wettability of the appliance.

To meet the demand for improved surface hardness, we attempted to produce a denture that combines softness with the ability to disperse biting pressure. Traditional methods for preparing the denture base resin include relining the elastic material used to construct the denture after the prosthesis has been made. To facilitate instantiation of the denture while maintaining a soft surface, we developed a new technique $^{4)}$ wherein the denture is modified to include a cushion constructed from elastic material. In this technique, differed from the common technique for adhering the elastic materials to the denture after the prosthesis has been made, a soft lining material is placed at a designated position on the tissue side of the denture and light-cured, followed by the addition of dough to the base resin. The silicone rubber lining materials in use at present, however, do not adhere well to acrylic denture base resins. Thus, primers and finishing materials are used to induce adherence, although the durability of these materials is poor ${ }^{5,6)}$.

Riggs et al. ${ }^{7)}$ proposed new soft lining materials composed of a butadiene/styrene copolymer gelled with methacrylate, but these materials exhibit high water uptake and signs of oxidation. Acrylic-type denture soft lining materials (Physio Soft Rebase; Nissin, Kyoto, Japan) composed of methacrylate monomers ${ }^{8)}$ bonded to an acrylic denture base resin without adhesive are available for heat-curing with heat-curing denture base resins; however, regulating the hardness and thickness of these products is difficult.

Our previous work $^{9}$ using different urethane acrylate oligomers suggested the formation of a strong bond between the urethane acrylate polymers and methyl methacrylate when an unpolymerized chemicalcuring methyl methacrylate mixture was poured onto the polymers and then cured. The urethane acrylate oligomers with terminal groups available for radical reactions possess a wide range of viscosities depending on the molecular weight and specific terminal group(s). Polymerized urethane oligomers also show diverse properties (from soft to hard). Furthermore, urethane acrylate oligomers can be polymerized using benzoyl peroxide or camphorquinone in much the same way as dental curing. Previously ${ }^{10)}$, we tested the mechanical properties of these materials by mixing urethane acrylate oligomers with methacrylates to control the viscosity, and we found that they were suitable for use in our new technique as soft lining materials. However, methacrylates showed higher volatile property than urethane acrylate oligomers. If there are some urethane acrylate oligomers which have suitable viscosity without methacrylates, that is advantage to keep the constant property in long-term storage.

In the present study, experimental light-curing soft lining materials (ESLMs) based on newly selected four urethane acrylate oligomers were prepared and their viscosity prior to polymerization, mechanical properties after polymerization, and cytotoxicity before and after polymerization were assessed. 


\section{MATERIALS AND METHODS}

\section{Materials}

Four urethane acrylate oligomers were used as components of ESLMs (Table 1). We added $0.5 \mathrm{wt} \%$ camphorquinone (Wako Pure Chemical, Osaka, Japan) as a photosensitizer and $0.5 \mathrm{wt} \%$ 2-(dimethylamino) ethylmethacrylate (Wako Pure Chemical) as a reducing agent to the urethane oligomers. A homogenizing machine (AR-100; Thinky, Tokyo, Japan) with highspeed rotation $(800 \mathrm{rpm})$ and orbital motion $(2200 \mathrm{rpm})$ was used to mix the materials in a darkened room. The each mixing time was $30 \mathrm{~s}$. The mixtures were stored in lightproof bottles.

\section{Measuring methods}

\section{Viscosity}

Before photopolymerization, the viscosity of each ESLM was measured five times at $25^{\circ} \mathrm{C}$ using a viscometer (ReoStress 600; Haake, Karlsruhe, Germany) on a cone plate at an angle of $1^{\circ}$ with $\mathrm{D}=20 \mathrm{~mm}$ and a shear rate of $10 \mathrm{~s}^{-1}$.

\section{Compressive modulus}

Each ESLM was poured into a polyethylene tube (11 $\mathrm{mm}$ in diameter $\times 10 \mathrm{~mm}$ in height) on a glass plate, and the top of the tube was covered with another glass plate. The material was then polymerized two times for $3 \mathrm{~min}$ each (once from the top and once from the bottom) using a light-curing unit ( $\alpha$-Light; Morita, Tokyo, Japan) composed of five quartz-tungsten halogen lamps. After removal from the polyethylene tube, the polymerized test specimen was stored in water at $37^{\circ} \mathrm{C}$ for $24 \mathrm{~h}$. A compression test was then performed at $37^{\circ} \mathrm{C}$ using a universal testing machine (TG-50kN; Minebea, Nagano, Japan) at a crosshead speed of $2 \mathrm{~mm} \mathrm{~min}-1$ in air, and the compressive modulus was calculated within the proportional limit.

\section{Hardness}

Test specimens were prepared as described above. The Shore A hardness was then measured with a durometer (GSD-709; Teclock, Nagano, Japan), fixed on a constant pressure load instrument (GS-710; Teclock), and loaded with a $1-\mathrm{kg}$ weight in air at $37^{\circ} \mathrm{C}$.

\section{Tensile strength}

Each ESLM was put into a silicone rubber mold with a dumbbell-type hollow $4 \mathrm{~mm}$ wide and $2 \mathrm{~mm}$ thick (No. 6 , JIS K 6251) $)^{11}$, and the surface was covered with polyethylene film. The irradiation and storage conditions described above were used for each of the following tests. After storage, a tensile strength test was performed at room temperature using a universal testing machine at a crosshead speed of $254 \mathrm{~mm} \mathrm{~min}{ }^{-1}$ and a gauge length of $20 \mathrm{~mm}$.

\section{Adhesive strength}

Each ESLM was placed in a silicone rubber mold 10 $\mathrm{mm}$ in diameter and $1 \mathrm{~mm}$ thick, and the surface was covered with polyethylene film. The irradiation conditions described above were used. After preparation with visible light and removal from the mold, the cured disk was placed in a polytetrafluoroethylene (PTFE) mold and sandwiched between two other PTFE molds (Fig. 1). A chemical-curing acrylic resin (Pour Resin; Shofu, Kyoto, Japan) was prepared as per the manufacturer's instructions, poured into a cylindrical hole, and cured at $50^{\circ} \mathrm{C}$ in an oven. After storage in water at $37^{\circ} \mathrm{C}$ for 1 day, 6 months, or 12 months, a tensile-adhesive test was performed at room temperature using a universal testing machine at a crosshead speed of $1 \mathrm{~mm} \mathrm{~min}^{-1}$.

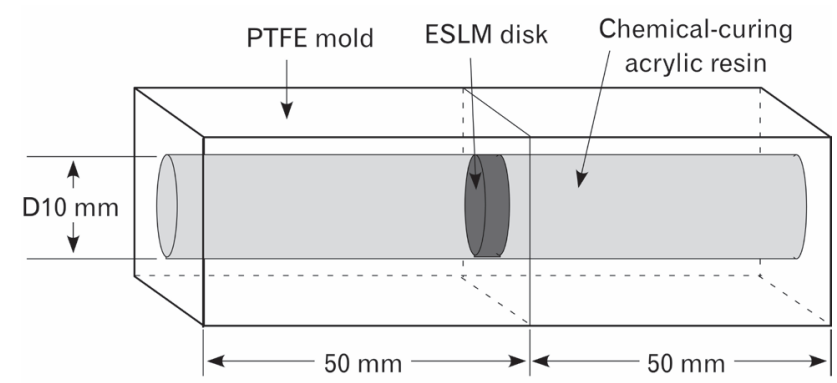

Fig. 1 Schematic representation of the methods used to make the test specimens and to test their adhesive strengths.

Table 1 Four urethane acrylate oligomers used in this investigation

\begin{tabular}{clcllc}
\hline Oligomer & \multicolumn{1}{c}{ Manufacturer } & Functional group & \multicolumn{1}{c}{ Type $^{*}$} & \multicolumn{1}{c}{ MW** } & Code \\
\hline UA-160TM & Shin-Nakamura Chem. ${ }^{*}$ & 2 & Methylene glycol & 1600 & UA-16 \\
UV-3200B & Nippon Synthetic Chem. ${ }^{2}$ & 2 & Ester & $10000<$ & UV-32 \\
UV-3500BA & Nippon Synthetic Chem. & 2 & Ester & $10000<$ & UV-35 \\
UV-3700B & Nippon Synthetic Chem. & 2 & Ether & $10000<$ & UV-37 \\
\hline
\end{tabular}

${ }^{1}$ Wakayama, Japan ${ }^{2}$ Osaka, Japan

* Manufacturer's information

**Average molecular weight by manufacturer's information 
Cytotoxicity (Cell viability)

The cytotoxicity was evaluated by the cell viability. Each ESLM was placed in a silicone rubber mold 34 $\mathrm{mm}$ in diameter and $1 \mathrm{~mm}$ thick, and the surface was covered with polyethylene film. The irradiation conditions described above were used. After preparation under visible light and removal from the mold, the cured disk was washed with distilled water for $30 \mathrm{~s}$. After drying for $5 \mathrm{~min}$, the disk was sterilized using ethylene oxide gas. Each disk was then soaked in Dulbecco's modified Eagle's medium (D-MEM) for 1 week. After soaking, HeLa S3 (human cervical carcinoma-derived) and Ca9-22 (human gingival carcinoma-derived) cells cultured in D-MEM containing $5 \%$ fetal bovine serum (FBS) were stimulated with the supernatants for 1 week and analyzed (model 680; BioRad, Hercules, CA, USA) for cell viability using the 3(4,5-dimethylthiazol-2yl)-2,5-diphenol tetrazolium bromide (MTT) assay. Cell viability was calculated using the following equation:

$$
\text { Cell viability }(\%)=[(A-B) /(C-B)] \times 100
$$

where $A$ is the absorbance of the cells in the extracted culture medium, $B$ is the absorbance of the culture medium (blank), and $C$ is the absorbance of a static cell.

\section{Statistical analysis}

One-way analysis of variance (ANOVA) and Tukey's test were performed for each test using five test specimens.

\section{RESULTS}

Fig. 2a-d show the viscosity, compressive modulus, Shore A hardness, and tensile strength of the four ESMLs, respectively. The viscosity of UV-35 was 10.5 Pas, which was the lowest value of the four ESLMs. The four ESLMs exhibited different levels of softness based on the results of our compressive and hardness tests. The compressive modulus, Shore A hardness, and tensile strength of polymerized UV-37 (0.81, 11.8, and $0.37 \mathrm{MPa}$, respectively) was the lowest among the four ESLMs.

Fig. 3 shows the adhesive strength of the four ESLMs against the chemical-curing acrylic resin. No significant difference in adhesive strength was observed between UV-35 and UV-37 at 1 day and 12 months $(p>0.01)$.

Fig. $4 \mathrm{a}$ and $\mathrm{b}$ show the degree of cell viability in the presence of the urethane acrylate oligomers and
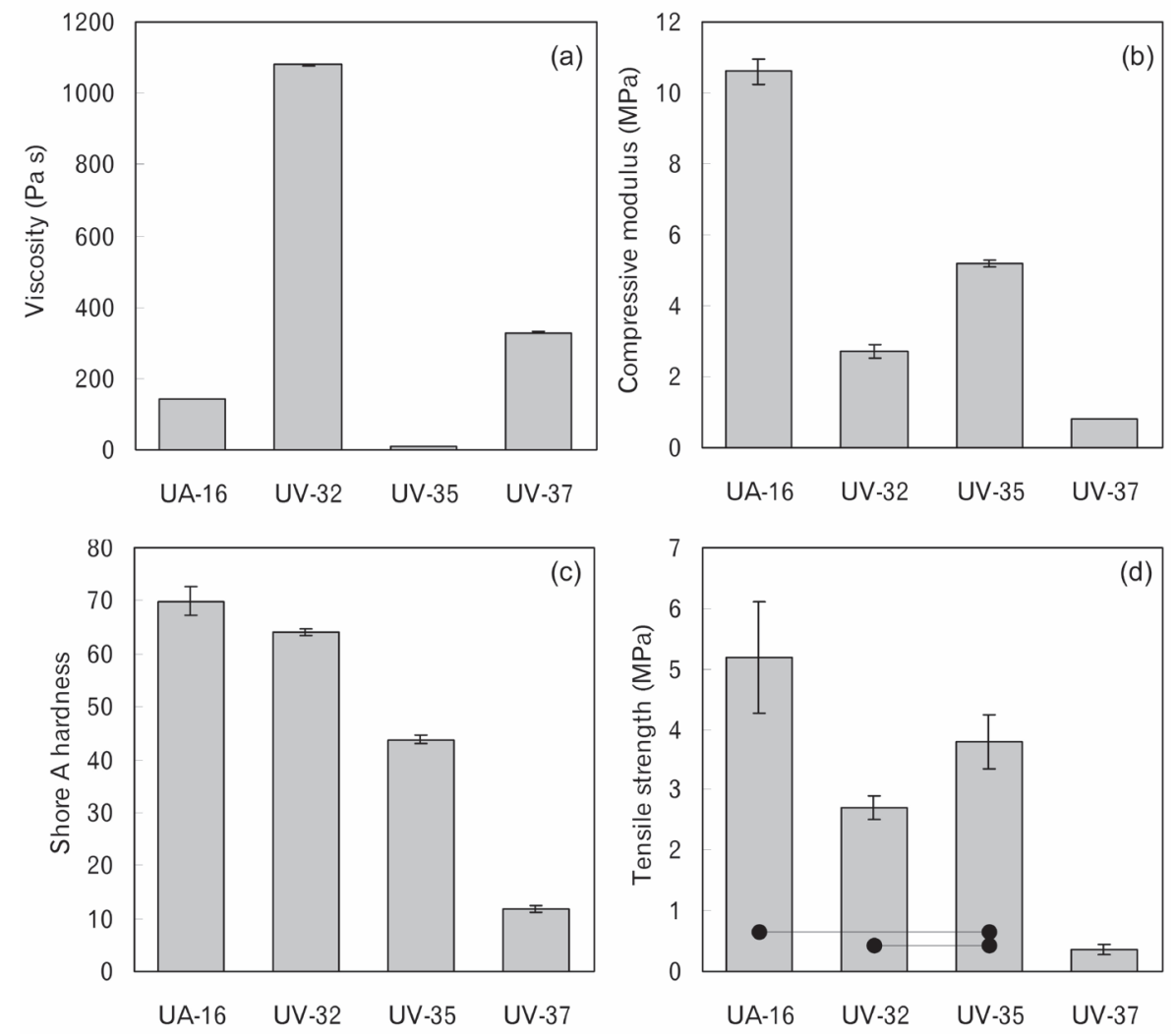

Fig. 2 The viscosities and mechanical properties of the four experimental soft lining materials (a: viscosity at $25^{\circ} \mathrm{C}$, b: compressive modulus at $37^{\circ} \mathrm{C}$, c: Shore A

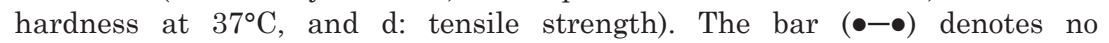
significant difference $(p>0.01)$ in all codes. 
four ESLMs. Cell viability in the presence of the polymerized ESLMs exceeded $95.2 \%$. Cell viability in the presence of the UA-16 oligomer was $15.9 \%$ for the HeLa S3 cells and 63.4\% for the Ca9-22 cells, whereas the values for polymerized UA-16 were 107.6 and $107.5 \%$, respectively.

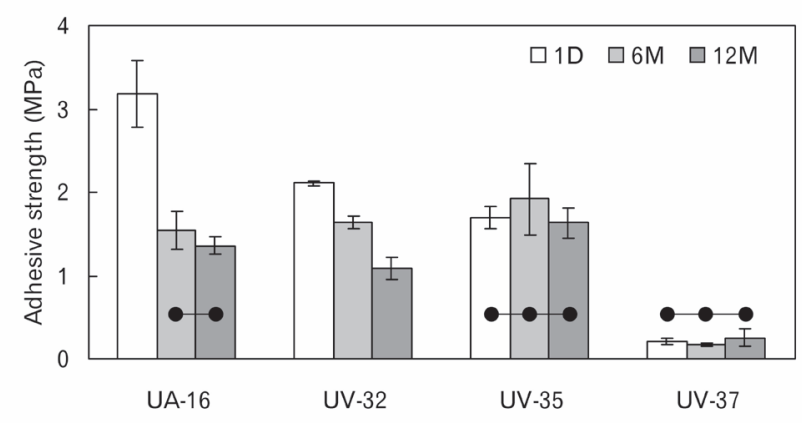

Fig. 3 Adhesive strengths of the four experimental soft lining materials after storage in water for 1 day (1 D), 6 months $(6 \mathrm{M})$, or 12 months $(12 \mathrm{M})$ at $37^{\circ} \mathrm{C}$.

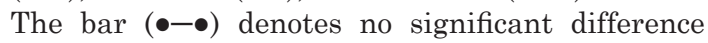
$(p>0.01)$ in the same code.
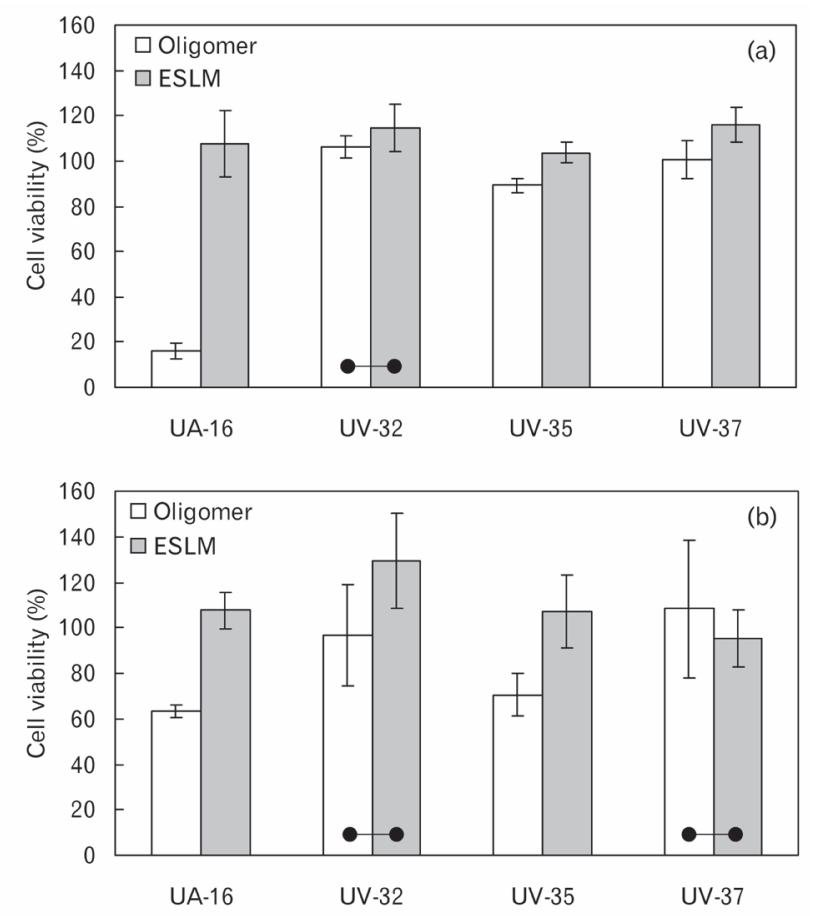

Fig. 4 Cell viability in the presence of the urethane acrylate oligomers and experimental soft lining materials (a: HeLa S3, b: Ca9-22). The bar $(\bullet-\bullet)$ denotes no significant difference $(p>0.05)$ in the same code.

\section{DISCUSSION}

As a base material of ESLMs for our new technique ${ }^{4)}$, four urethane acrylate oligomers were selected under condition that it is polymerized by radical reactions in much the same way as dental visible light curing, it is manipulated by a spatula or fingers on the model, and it possesses softness based on elasticity after polymerization. In this investigation, commercial urethane acrylate oligomers were used, because there is much type and they are easily available.

The viscosity of the urethane acrylate oligomer is an important factor in our technique ${ }^{4)}$ because ESLMs are applied with a spatula and then modified by hand using a thin polyethylene film before polymerization. From our preliminary tests, our ideal value of the viscosity was from 200 to $1000 \mathrm{~Pa} \cdot \mathrm{s}$ at $25^{\circ} \mathrm{C}$. This range was determined based on the poll using the 1 to 5 scale of ten dental technicians who manipulated oligomers with varying viscosities from 40 to $1400 \mathrm{~Pa} \cdot \mathrm{s}$ according to the requirement for sufficient operativity and non-flowability on the working model. In the present study, the viscosity of UA-32 was in this range and that of UV-32 and UV-37 was nearby to this range, whereas the viscosity of UV-35 $(10.5 \mathrm{~Pa} \cdot \mathrm{s})$ was below this range. Thus, if UV-35 is to be used in this new technique, the viscosity should be increased by the addition of a soft-type polymer powder, such as polymethacrylate or polyurethane.

Elasticity is another important factor for soft lining materials. In this study, the compressive modulus and hardness of UA-16, UV-32, and UV-35 were similar to those of commercial silicone rubber-type or acrylic-type soft lining materials. The compressive modulus and hardness of UV-37 were lower than those of the other three ESLMs. In fact, the values for UV-37 were similar to those reported for denture adhesives and home reliners ${ }^{12,13)}$. Thus, UV-37 might be acceptable for those complete denture users who prefer denture adhesives or home reliners. Denture adhesives and home reliners contribute to reduced denture movement and exhibit greater retentive ability than saliva, but they must be replaced daily. Softer lining materials would fit better with the oral mucosa, but extremely soft materials would likely make it difficult to chew some foods. No standard currently exists for the elasticity or softness of denture base lining materials; thus, additional studies are needed.

Previously ${ }^{14)}$, the tensile strength of commercially available and experimental silicone soft lining materials was reported to be 2.12 and $5.20 \mathrm{MPa}$, respectively. In that report, a testing speed of $500 \mathrm{~mm}$ min $^{-1}$ was employed; thus, the tensile strength may have been a little higher than $254 \mathrm{~mm} \mathrm{~min}^{-1}$. Moreover, whether tensile strength has a direct impact on denture use is unclear, but it is an important factor since adhesive tensile strength should never exceed ordinary tensile strength. The tensile strength of UV-37 was $0.37 \mathrm{MPa}$, which is lower than that of the other ESLMs. Thus, UV-37 should not be subjected to large 
tensile forces.

At present, silicone rubber-type and acrylic-type soft lining materials are used in dentistry, although these materials exhibit problems with durability. Acrylic lining materials tend to harden due to a loss of plasticizer in the mouth or polymerization by residual monomers ${ }^{15,16)}$. As silicone rubber materials do not adhere well to acrylic denture base resins, primers and finishing materials are used to induce adherence. However, the life expectancy of these materials is typically only a few months ${ }^{5,6}$. One of the aims of this study was to increase the durability of soft lining materials. The urethane acrylate oligomers used in this investigation are meant to serve as a binder for plastics and a coating material. We tested the ESLM specimens after 12 months of storage in water at $37^{\circ} \mathrm{C}$. No significant difference in adhesive strength was observed between UV-35 and UV-37 after 1 day or 12 months $(p>0.01)$, and cohesive failure in the four ESLMs was detected. This indicates sufficient bonding at the interface between the acrylate resin and ESLM. Thus, the four ESLMs would be expected to exhibit long-term adhesiveness. Tight adhesion between the polymerized soft lining material and acrylic denture base resin is a critical factor in the success of our new technique, which has several advantages: it can laminate ESLMs with different elastic moduli, create ESLMs with different elastic moduli, and change the elasticity both inside and outside like a functional gradient material.

As cytotoxicity is also a critical factor for dental materials, the biogenic safety of these ESLMs must be confirmed. At present, the biocompatibility of the commercial urethane acrylate oligomers used in industrial chemistry has not been confirmed. Previous studies using dental composite resins revealed the following hierarchy of cytotoxicity: bisphenol glycidyl methacrylate (Bis-GMA) monomer > urethane dimethacrylate (UDMA) monomer > methyl methacrylate monomer ${ }^{17,18)}$; moreover, the presence of a hydroxyl group was shown to enhance the cytotoxicity of acrylates and methacrylates ${ }^{19)}$. UDMA monomer is less cytotoxic than Bis-GMA monomer, but UDMA may exist as several types of monomers or oligomers depending on its terminal group. Several studies have considered the cytotoxicity of urethane acrylate oligomers. Nassiri et al. ${ }^{20)}$ measured the cytotoxicity of urethane dimethacrylate oligomers using flow cytometry (FCM), but the aim of that study was to show that FCM is a practical approach for analyzing cytotoxicity. Other reports ${ }^{21-23}$ have used MTT-based assays to analyze dental composites. We also employed a MTT assay, which is sensitive and exhibits minimal variation. Two methods can be applied to obtain an extract medium: direct seeding of cells onto the sample and the culturing of cells with an extract prepared from a mixture of sample and culture. In the former method, the polyurethane disk and cells are mixed in a cultureplate. We employed the latter method because using the former method to ensure close contact between the cells and polyurethane disk is difficult.

We followed the guidelines ${ }^{24}$ set forth by the Ministry of Health, Labour and Welfare (MHLW) of Japan in performing our cytotoxicity tests. Under those guidelines, HeLa S3 cells must be used to test the cytotoxicity of denture base lining materials; however, we also used Ca9-22 cells, which are derived from the human gingiva, because denture base lining materials are used in contact with the oral gingiva. Cell viability in the presence of the polymerized ESLMs was 100\%, except for UV-37, which showed a value of $95.2 \%$ for Ca9-22 cells. No significant difference was observed between the base oligomer and ESLM in the presence of UV-37 using Ca9-22 cells. Based on these results, the polymerized ESLMs generally showed less cytotoxicity. The base urethane acrylate oligomers of UV-32 and UV-37 showed 105.9 and $100.6 \%$ cytotoxicity using HeLa S3 cells and 96.9 and $108.3 \%$ cytotoxicity using Ca9-22 cells. This indicates the utility of the two oligomers as an experimental soft lining material because most oligomers contain some residual oligomers after polymerization.

We were unable to determine why the degree of cell viability was so low in the presence of oligomers of UA-16 and UV-35. One of the aims of this investigation was to reveal the level of cytotoxicity for each of the four ESLMs. To obtain this, information on the structural formula of each urethane acrylate oligomer is needed, as is further analysis of the terminal groups.

Based on our viscosity measurements, UA-16, UV32 , and UV-37 have sufficient operativity and nonflowability for use on model plaster. UA-16, UV-32, and UV-35 showed a similar degree of softness with conventional soft lining materials; moreover, UV-37 was found to be very soft, similar to denture adhesives or home reliners. The ESLMs tested showed cohesive failure, and no decrease in adhesive strength was observed for UV-35 and UV-37 after 1 day and 12 months. The polymerized ESLMs generally showed cell viability over $95.2 \%(p<0.05)$. In conclusion, the four ESLMs tested are suitable for use as the soft lining material in our new technique.

\section{ACKNOWLEDGMENTS}

We thank Mr. Yasuki Takenouchi and the staff of the A Dental Laboratory for their cooperation in determining the viscosity range of the experimental soft lining materials. We thank The Nippon Synthetic Chemical Industry Co.,Ltd. for providing the urethane acrylate oligomers. We also thank Dr. Ayako Takenaka for providing technical assistance.

This work was partially supported by a grant from the R\&D matching fund of NEDO and by a Grant-inAid for Scientific Research (No. 17592031) from the Japan Society for the Promotion of Science.

\section{REFERENCES}

1) Coates AJ. Usage of denture adhesives. J Dent 2000; 28: 
$137-140$

2) Grasso JE. Denture adhesives. Dent Clin North Am 2004; 48: 721-733.

3) Sato Y, Kaiba Y, Hayakawa I. Evaluation of denture retention and ease of removal from oral mucosa on a new gel-type denture adhesive. J Jpn Prosthodont Soc 2008; 52: 175-182.

4) Kanie T, Kadokawa A, Arikawa H, Fujii K, Ban S. Mechanical properties of an experimental soft lining material based on urethane oligomer. Dent Mater J 2005; 24: 433-439.

5) Sertgoz A, Kulak Y, Gedik H, Taskonak B. The effect of thermocycling on peel strength of six soft lining materials. J Oral Rehabil 2002; 29: 583-587.

6) Tanimoto Y, Saeki H, Kimoto S, Nishiwaki T, Nishiyama N. Evaluation of adhesive properties of three resilient denture liners by the modified peel test method. Acta Biomat 2009; 5: 764-769.

7) Riggs PD, Parker S, Braden M, Kalachandra S. Development of novel elastomer/methacrylate monomer soft lining materials. J Mater Sci Mater Med 2001; 12: 359-364.

8) Manufacturer's instruction.

9) Kanie T, Arikawa H, Fujii K, Ban S. Light-curing reinforcement for denture base resin using a glass fiber cloth pre-impregnation with various urethane oligomers. Dent Mater J 2004; 23: 291-296.

10) Kanie T, Kadokawa A, Arikawa H, Fujii K, Ban S. Effects of adding methacrylate monomers on viscosity and mechanical properties of experimental light-curing soft lining materials based on urethane (meth)acrylate oligomers. Dent Mater J 2008; 27: 856-861.

11) Japanese Standards Association. JIS Handbook 19 Rubber, Japanese Standards Association, Tokyo, 1993, pp. 107-112.

12) Fujimori T, Nakano F, Takahashi H, Iwasaki N, Nishimura F, Hayakawa I. Effects of adherend on retentive force using denture adhesives and home-reliners. Dent Mater J 2002; 21: 368-375.

13) Murata H, Yamakado C, Hamada T. Dependence of dynamic viscoelastic properties on frequency for denture adhesives. Dent Mater J 2004; 23: 371.
14) Waters MG, Jagger RG. Mechanical properties of an experimental denture soft lining material. J Dent 1999; 27: 197-202.

15) Braden M, Wright PS, Parker S. Soft lining materials-a review. Eur J Prosthodont Restor Dent 1995; 3: 163-174.

16) Fujii K, Arikawa H, Kanie T, Shinohara N, Inoue K. Effect of photo-irradiation on hardness of soft lining materials for denture base. J Oral Rehabil 2002; 29: 744-748.

17) Jontell M, Hanks CT, Bratel J, Bergenholtz G. Effects of unpolymerized resin components on the function of accessory cells derived from the rat incisor pulp. J Dent Res 1995; 74: 1162-1167.

18) Ratanasathien S, Wataha JC, Hanks CT, Dennison JB. Cytotoxic interactive effects of dentin bonding components on mouse fibroblasts. J Dent Res 1995; 74: 1602-1606.

19) Yoshii E. Cytotoxic effects of acrylates and methacrylates: relationships of monomer structures and cytotoxicity. J Biomed Mater Res 1997; 37: 517-524.

20) Nassiri MR, Hanks CT, Cameron MJ, Strawn SE, Craig RG. Application of flow cytometry to determine the cytotoxicity of urethane dimethacrylate in human cells. J Biomed Mater Res 1994; 28: 153-158.

21) Bean TA, Zhuang WC, Tong PY, Eick JD, Chappelow CC, Yourtee DM. Comparison of tetrazolium colorimetric and $51 \mathrm{Cr}$ release assays for cytotoxicity determination of dental biomaterials. Dent Mater 1995; 11: 327-331.

22) Sigusch BW, Volpel A, Braun I, Uhl A, Jandt KD. Influence of different light curing units on the cytotoxicity of various dental composites. Dent Mater 2007; 23: 1342-1348.

23) Brackett MG, Bouillaguet S, Lockwood PE, Rotenberg S, Lewis JB, Messer RL, Wataha JC. In vitro cytotoxicity of dental composites based on new and traditional polymerization chemistries. J Biomed Mater Res Appl Biomat 2007; 81: 397-402.

24) Supervision of Medical Devices Division of the Pharmaceutical Affairs Bureau. Guideline of physical, chemical and biological study for dental materials. Japan Association for the Advancement of Medical Equipment (JAAME), Tokyo, 1997, pp. 40-1. 